\title{
Hypertension (HTN) Knowledge and with Its Associated Factors: About 456 Outpatients Seen in Cardiology Department in University Hospital (UH) Gabriel Touré-Bamako (Mali)
}

\author{
Hamidou Oumar Bâ1*, Ichaka Menta1, Ibrahima Sangaré1, Youssouf Camara², \\ Georges Rosario Christian Millogo ${ }^{3}$, Noumou Sidibé ${ }^{1}$, Ilo Bella Diall ${ }^{4}$, Souleymane Coulibaly4, \\ Guida Landouré4, Mandé Berthé1, Ibrahim Maiga1, Bréhima Mariko1, Cheick Hamala Fofana1, \\ Aladji Traoré1, Kassoum Mamourou Sanogo ${ }^{1}$
}

\author{
${ }^{1}$ CHU Gabriel Touré Bamako, Bamako, Mali \\ ${ }^{2} \mathrm{CHU}$ Kati, Bamako, Mali \\ ${ }^{3} \mathrm{CHU}$ YO-Ouagadougou, Ouagadougou, Burkina-Faso \\ ${ }^{4} \mathrm{CHU}$ Point G, Bamako, Mali \\ Email: ^bhamiba@yahoo.fr
}

\begin{abstract}
How to cite this paper: Bâ, H.O., Menta, I., Sangaré, I., Camara, Y., Millogo, G.R.C., Sidibé, N., Diall, I.B., Coulibaly, S., Landouré, G., Berthé, M., Maiga, I., Mariko, B., Fofana, C.H., Traoré, A. and Sanogo, K.M. (2018) Hypertension (HTN) Knowledge and with Its Associated Factors: About 456 Outpatients Seen in Cardiology Department in University Hospital (UH) Gabriel Touré-Bamako (Mali). World Journal of Cardiovascular Diseases, 8, 24-34. https://doi.org/10.4236/wjcd.2018.81004
\end{abstract}

Received: December 15, 2017 Accepted: January 16, 2018 Published: January 19, 2018

Copyright $\odot 2018$ by authors and Scientific Research Publishing Inc. This work is licensed under the Creative Commons Attribution International License (CC BY 4.0).

http://creativecommons.org/licenses/by/4.0/ c)

\begin{abstract}
Background: High Blood Pressure (HBP) is high prevalent among adult population in Bamako, but little is known about factors associated with knowledge. Methods: It was a cross-sectional study involving patients aged 15 years and more with a first classification in normal blood pressure (HTN-) and high blood pressure $(\mathrm{HTN}+)$, and Second classification inpatients without knowledge (who answered No) $(\mathrm{K}-$ ) and patients with knowledge (who answered Yes) $(\mathrm{K}+)$. A logistic regression was performed to look up predictors among different variables. Results: The sample involved 456 patients with a mean age of 51.39 years and $65.1 \%$ of female. The age group $45-59$ years old made $32.5 \%$ and unschooled patients $60.3 \%$. Patients with HBP accounted for $69.7 \%$ and those reporting to know about it $67.3 \%$. HTN- and HTN + differed significantly except for HR, height, sex and level of schooling. HBP prevalence increased with age up to 74 years. Regarding knowledge, sex, age group and number of FDRs did not differ significantly. High education level and duration of HBP was predictive of knowledge with an OR of 1.186 [CI 0.058 0.796 ] and 1.192 [CI $0.332-4.275$ ] respectively. Conclusions: Our study provided data on HBP knowledge among outpatients with high educational level and HBP duration associated with better knowledge on HBP.
\end{abstract}

\section{Keywords}

Hypertension, Knowledge, Outpatient, Bamako, Cardiology 


\section{Background}

Hypertension (HTN), a major cardiovascular risk factor, is a global public health problem with nearly $25 \%$ prevalence in 2000 . Developing countries (DCs) and middle-income countries (MICs) had nearly 640 million cases of hypertension [1] of which nearly 80 millions resided in Sub-Saharan Africa (SSA) [2].

There were many studies of knowledge about HTN in the world. So was knowledge about hypertension determinants high in Germany [3] opposed to findings in Africa with lower rate of awareness [4]. Awareness rate remains low despite increasing prevalence of HTN [5]. Further some studies found improvements in awareness similar among people who had or did not have cardiovascular comorbidities [6]. Other authors found that unawareness differs by sex [7].

Common to all these studies is the use of either self reported health information or administrated formularies in survey. A direct comparison is difficult.

Factors known to be associated with awareness, knowledge of HTN are family history of HTN, overweight, worker status [8], marital status, education, health status, periodically reading books, newspapers or other materials, history of blood pressure measurement, and attending hypertension educational sessions [9].

Although HTN has been widely clinically studied [10] [11] [12] [13] [14], studies about patient knowledge are rare, in the West African sub-region.

In a previous study, we studied patients' level of knowledge about hypertension and its consequences [15], without searching for determinants of this knowledge.

There is a lack of data on HTN knowledge determinants which must be considered in decisions for HTN prevention and management. These facts have motivated our study which aims to study knowledge about hypertension as well as factors associated with this knowledge.

\section{Methods}

This cross-sectional study was performed in the Department of Cardiology of the University Hospital (UH) Gabriel Touré in Bamako from 01.12.2009 to 31.01.2010.

It involved all outpatients aged 15 years and older who consented to participate in the study. Minimal data were collected just necessary to keep track of each patient. All patients seen in the study period accepted to participate.

\section{Sample size:}

It was calculated using the formula:

$$
n=Z^{2} p q / i^{2} \times d
$$

with $n=$ sample size, $Z=1.96, p=30 \%=0.30, q=1-p=0.7, i=3 \%=0.03, d=$ 2 .

$n$ was calculated to be 448 patients. 


\section{Collected data:}

We used a dedicated formulary to collect demographics, past history, data on physical examination and anthropometric measurements (blood pressure, weight, height, heart rate). Furthermore this formulary had questions (opened and closed) on the perception of HTN, diabetes and hypercholesterolemia.

\section{Definitions:}

- HTN was defined for blood pressure $\geq 140 / 90 \mathrm{mmHg}$.

- Body mass index (BMI) was calculated for each patient through Weight in Kg divided by Height in $\mathrm{m}$ squared.

- Pulsed pressure (PP) was calculated as difference between systolic and diastolic blood pressure.

- Mean arterial pressure (MAP) was assessed through diastolic blood pressure (DBP) and systolic blood pressure (SBP) using the formula:

$\mathrm{DBP}+((\mathrm{SBP}-\mathrm{DBP}) / 3)$

Investigation of knowledge about hypertension:

Patient's knowledge and attitudes about hypertension were collected through a series of questions:

1) Do you know HTN?

a) Yes b) No

2) If yes, what is it?

3) HTN duration in months

4) What is your blood pressure?

5) What was your last blood pressure?:

6) How was your HTN discovered?

a) Fortuite b) Signs c) Complications

If complications, which?

7) Time interval of blood pressure check:

a) Weeks b) Months c) Years d) Irregularly

8) HTN treatment:

a) Yes b) No

Regularity: a) Yes b) No

What type of treatment: Medical Traditional both

9) Did you get information on HTN? a) Yes b) No

If Yes Source: Physician Other health personal Family member Other:

10) Did you asked your physician for information on HTN?

a) Yes b) No

11) What causes HTN?
a)
b)
c)
d

12) Which type of complications can HTN lead to?

a) Heart b) Brain c) Kidney d) Eyes e) Others:

13) Did you check your blood pressure outside of health facilities?

a) Yes b) No

If yes, where? 
14) Do you have a blood pressure apparatus:

a) Yes b) No

15) Do you think that physical activity has an effect on HTN?

a) Yes b) No

16) Which physical activity do you practice?

\section{Classifications:}

A first classification concerned blood pressure with:

- HTN- meaning no HTN and

- HTN+ patients with HTN.

Then HTN+ patients were divided in two groups according to the answer No or Yes to the question "Do you know hypertension?":

- Patients without knowledge (who answered No) (K-).

- Patients with knowledge (who answered Yes) $(\mathrm{K}+$ ) as shown below.

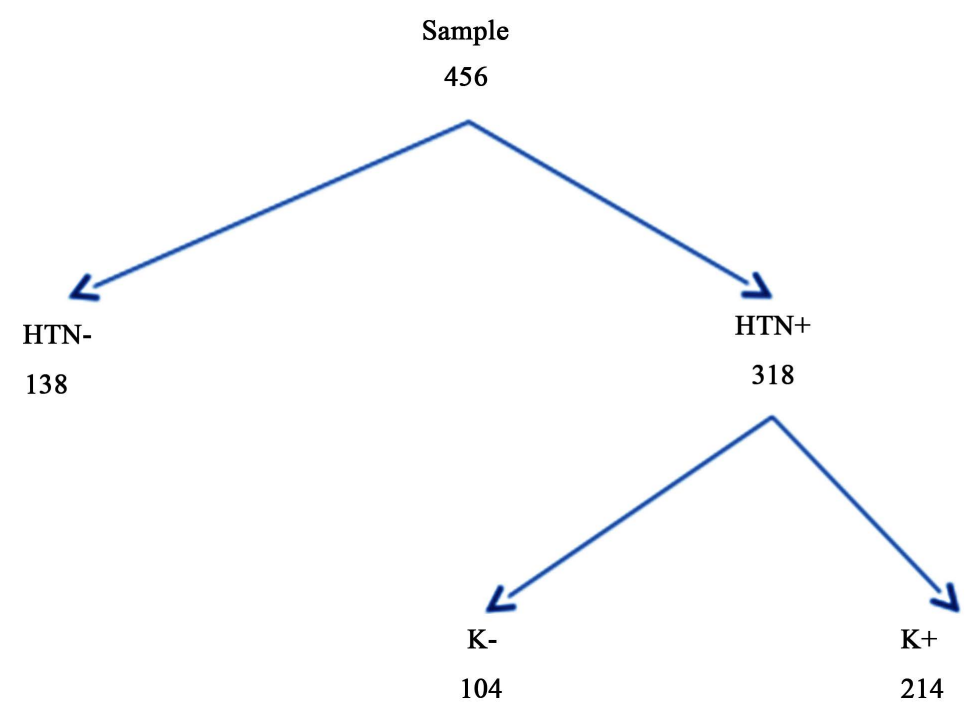

\section{Data processing:}

After sample description, univariate analyses of association between sociodemographic characters and cardiovascular risk factors versus knowledge were performed. Finally, a logistic regression for searching HTN knowledge associated factors among hypertensive patients was performed.

Collected data were recorded in a Microsoft Access Database, preliminary treated with Excel and finally imported in SPSS version 20 for analysis.

\section{Results}

The sample consisted of 456 patients with a mean age of 51.39(45.36 years +/18.139 for the HTN- group and $54.01+/-14.240$ for the HTN+ group), a mean BMI $25.22 \mathrm{~kg} / \mathrm{m}^{2}$ (23.495 for the HTN-group and 25.887 for the HTN+ group). Both age and BMI were significantly higher in the HTN+ group. Higher values were also found in the HTN+ group for blood pressure hemodynamic parameters (Table 1 ). 
Table 1. Sample description for 456 outpatients seen in cardiology department.

\begin{tabular}{|c|c|c|c|c|c|c|c|c|c|c|c|c|c|}
\hline & \multicolumn{4}{|c|}{ HTN- } & \multicolumn{4}{|c|}{ HTN+ } & \multicolumn{4}{|c|}{ Total } & \multirow{2}{*}{$p$} \\
\hline & Min. & Mean & Max. & SD & Min. & Mean & Max. & $S^{*}$ & Min. & Mean & Max. & $\mathrm{SD}^{*}$ & \\
\hline Age & 16 & 45.36 & 87 & 18.139 & 17 & 54.01 & 90 & 14.240 & 16 & 51.39 & 90 & 16.006 & $<0.0001$ \\
\hline Weight & 40 & 66.88 & 121 & 16.467 & 37 & 71.94 & 131 & 16.884 & 37 & 70.41 & 131 & 16.902 & 0.003 \\
\hline Height & 152 & 167.82 & 192 & 8.173 & 152 & 166.76 & 187 & 7.197 & 152 & 167.08 & 192 & 7.512 & 0.168 \\
\hline BMI & 13.72 & 23.495 & 44.08 & 5.479 & 14.45 & 25.887 & 44.96 & 6.147 & 13.72 & 25.222 & 45 & 5.895 & $<0.0001$ \\
\hline SBP & 80 & 134.11 & 200 & 24.796 & 100 & 161.85 & 260 & 29.285 & 80 & 153.45 & 260 & 30.746 & $<0.0001$ \\
\hline DBP & 60 & 85.70 & 140 & 13.799 & 60 & 98.38 & 160 & 16.249 & 60 & 94.54 & 160 & 16.593 & $<0.0001$ \\
\hline PP & 20 & 48.41 & 100 & 17.211 & 20 & 63.46 & 140 & 21.008 & 20 & 58.91 & 140 & 21.085 & $<0.0001$ \\
\hline MAP & 67 & 101.83 & 147 & 16.311 & 73 & 119.54 & 193 & 19.074 & 67 & 114.18 & 193 & 19.997 & $<0.0001$ \\
\hline HR & 52 & 87.80 & 154 & 17.203 & 52 & 86.66 & 180 & 17.430 & 52 & 87.01 & 180 & 17.287 & 0.521 \\
\hline
\end{tabular}

Female patients made $65.1 \%$, 45 - 59 years group $32.5 \%$ and unschooled patients $60.3 \%$ of the sample. $59 \%$ of the patients came from other health care centers (through reference) while $41 \%$ were intra-references (from others department from the UH Gabriel Touré) (Table 2).

Hypertensive patients accounted for $69.7 \%$ and those with knowledge about HTN 67.3\%.

Normotensive and hypertensive patients differed significantly except for heart rate (HR), height (Table 1), sex and level of schooling (Table 2). HBP prevalence increased with age up to 74 years. Most hypertensive patients were found among those with a high school education.

Hypertensive patients had more other risk factors except for smoking and physical inactivity compared to those without HTN (Table 3).

Family HTN and diabetes were more significantly found among hypertensive patients with p-value of 0.0001 and 0.034 (Diagram 1) and $77.80 \%$ of these patients reportedly had knowledge on HTN compared to $57.5 \%$ of HTN- patients (Diagram 2).

Although patients said they had knowledge about hypertension, there was some misinterpretation. So $33 \%$ could not define HTN, $20 \%$ used "excess of blood" that could be translated into the concept of volemia (Diagram 3).

The proportion of $\mathrm{HTN}+$ patients increased with the level of education from $55.6 \%$ for unschooled patients to $87.5 \%$ for patients with a higher education level $(<0.0001)$. There was no significant difference in sex, age group and number of risk factors (Table 4 ).

After exclusion of patients who could not provide duration of their HTN, a logistic regression analysis was performed. Among factors with a significant difference in knowledge, only the level of education and duration of HTN allowed prediction of knowledge after logistic regression (Table 5). Unschooled patient as reference, high level was predictive of knowledge about HTN (OR 1.186 [0.058 - 0.796]). 


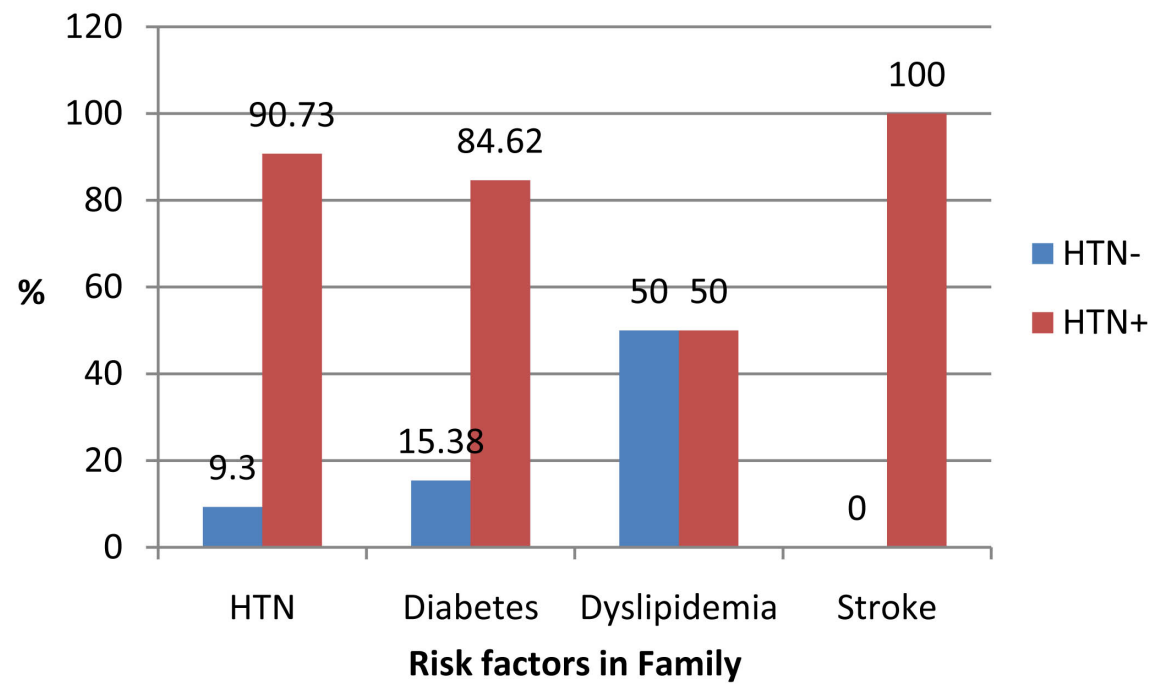

Diagram 1. Repartition of risk factors in the family. HTN $p<0.0001$ Diabetes $p=0.034$.

Table 2. Socio-demographics and cardiovascular risk factors of 456 outpatients seen in cardiology department.

\begin{tabular}{|c|c|c|c|c|c|}
\hline \multicolumn{2}{|l|}{ Variables } & \multirow{2}{*}{$\begin{array}{c}\text { HTN- } \\
\text { N(\%) }\end{array}$} & \multirow{2}{*}{$\begin{array}{c}\text { HTN+ } \\
\text { N(\%) }\end{array}$} & \multirow{2}{*}{$\begin{array}{c}\text { Total } \\
\text { N (\%) } \\
159(34.9)\end{array}$} & \multirow{2}{*}{$\begin{array}{c}p \\
0.208\end{array}$} \\
\hline Sex & Male & & & & \\
\hline & Female & $084(60.9)$ & $213(67.0)$ & $297(65.1)$ & \\
\hline \multirow[t]{5}{*}{ Age group (years) } & $15-29$ & $32(23.2)$ & $13(04.1)$ & $45(09.9)$ & \\
\hline & $30-44$ & $36(26.1)$ & $71(22.3)$ & $107(23.5)$ & \\
\hline & $45-59$ & $35(25.4)$ & $113(35.5)$ & $148(32.5)$ & $<0.0001$ \\
\hline & $60-74$ & $23(16.7)$ & $93(29.2)$ & $116(25.4)$ & \\
\hline & $\geq 75$ & $12(08.7)$ & $28(08.8)$ & $40(08.8)$ & \\
\hline \multirow[t]{4}{*}{ Level of education } & Unschooled & $88(63.8)$ & $187(58.8)$ & $275(60.3)$ & \multirow{4}{*}{0.254} \\
\hline & Primary & $22(15.9)$ & $57(17.9)$ & $79(17.3)$ & \\
\hline & Secondary & $17(12.3)$ & $58(18.2)$ & $75(16.4)$ & \\
\hline & High & $11(08.0)$ & $16(05.0)$ & $27(05.9)$ & \\
\hline \multirow[t]{6}{*}{ Number of risk factors } & 0 & $115(83.3)$ & $00(0.0)$ & $115(25.2)$ & \multirow{6}{*}{$<0.0001$} \\
\hline & 1 & $13(09.4)$ & $229(72.0)$ & $242(53.1)$ & \\
\hline & 2 & $09(06.5)$ & $51(16.0)$ & $60(13.2)$ & \\
\hline & 3 & $01(0.7)$ & $29(09.1)$ & $30(06.6)$ & \\
\hline & 4 & $00(0.0)$ & $07(02.2)$ & $07(01.5)$ & \\
\hline & 5 & $00(0.0)$ & $02(0.6)$ & $02(0.4)$ & \\
\hline \multirow{2}{*}{ HTN in family } & No & $115(83.3)$ & $93(29.2)$ & $208(45.6)$ & \multirow[b]{2}{*}{$<0.0001$} \\
\hline & Yes & $23(16.7)$ & $225(70.8)$ & $248(54.4)$ & \\
\hline
\end{tabular}


Table 3. Other risk factors in the sample of 456 patients (138 HTN- and $318 \mathrm{HTN}+$ ).

\begin{tabular}{ccccc}
\hline Variables & $\begin{array}{c}\text { HTN- } \\
\text { N(\%) }\end{array}$ & $\begin{array}{c}\text { HTN+ } \\
\text { N(\%) }\end{array}$ & $\begin{array}{c}\text { Total } \\
\text { N (\%) }\end{array}$ & $p$ \\
\hline Diabetes mellitus & $01(0.7)$ & $29(09.1)$ & $30(06.6)$ & 0.001 \\
Dyslipidemia & $01(0.7)$ & $04(01.3)$ & $05(01.1)$ & 0.688 \\
Tabacco smoking & $15(10.9)$ & $31(09.7)$ & $46(10.1)$ & 0.736 \\
Alcohol consumption & $04(02.9)$ & $01(0.3)$ & $05(01.1)$ & 0.031 \\
Sedentarity & $01(0.7)$ & $10(03.1)$ & $11(02.4)$ & 0.185 \\
Obesity & $06(04.3)$ & $35(11.0)$ & $41(09.0)$ & 0.031 \\
Stroke & $01(0.7)$ & $25(07.9)$ & $26(05.7)$ & 0.001 \\
\hline
\end{tabular}

Table 4. Socio-demographics and risk factors of 318 HTN related to knowledge on HTN.

\begin{tabular}{|c|c|c|c|c|}
\hline Variables & & $\begin{array}{c}\mathrm{K}- \\
\mathrm{N}(\%)\end{array}$ & $\begin{array}{c}\mathrm{K}+ \\
\mathrm{N}(\%)\end{array}$ & $p$ \\
\hline \multirow[t]{2}{*}{ Sex } & Male & $34(32.4)$ & $71(67.6)$ & \\
\hline & Female & $70(32.9)$ & $143(67.1)$ & 0.931 \\
\hline \multirow[t]{5}{*}{ Age group (years) } & $15-29$ & $2(15.4)$ & $11(84.6)$ & \\
\hline & $30-44$ & $20(28.2)$ & $51(71.8)$ & \\
\hline & $45-59$ & $35(31.0)$ & $78(69.0)$ & \\
\hline & $60-74$ & $32(34.4)$ & $61(65.6)$ & \\
\hline & $\geq 75$ & $15(53.6)$ & $13(46.4)$ & 0.083 \\
\hline \multirow[t]{4}{*}{ Level of education } & Unschooled & $83(44.4)$ & $104(55.6)$ & \\
\hline & Primary & $10(17.5)$ & $47(82.5)$ & \\
\hline & Secondary & $9(15.5)$ & $49(84.5)$ & \\
\hline & High & $2(12.5)$ & $14(87.5)$ & $<0.0001$ \\
\hline \multirow[t]{2}{*}{ Origin } & Home & $52(39.4)$ & $80(60.6)$ & \\
\hline & Adressed & $52(28.0)$ & $134(72.0)$ & $<0.0001$ \\
\hline \multirow[t]{5}{*}{ Number of risk factors } & 1 & $83(36.2)$ & $146(63.8)$ & \\
\hline & 2 & $16(31.4)$ & $35(68.6)$ & \\
\hline & 3 & $3(10.3)$ & $26(89.7)$ & \\
\hline & 4 & $1(14.3)$ & $6(85.7)$ & \\
\hline & 5 & $1(50.0)$ & $1(50.0)$ & 0.054 \\
\hline \multirow[t]{2}{*}{ HTN in family } & No & $37(39.8)$ & $56(60.2)$ & \\
\hline & Yes & $67(29.8)$ & $158(70.2)$ & 0.084 \\
\hline \multirow[t]{7}{*}{ HTA duration (months) } & $\mathrm{NA}^{* *}$ & $28(59.6)$ & $19(40.4)$ & \\
\hline & $<6$ & $19(43.2)$ & $25(56.8)$ & \\
\hline & $6-12$ & $16(37.2)$ & $27(62.8)$ & \\
\hline & $13-24$ & $12(35.3)$ & $22(64.7)$ & \\
\hline & $25-36$ & $9(20.9)$ & $34(79.1)$ & \\
\hline & $37-48$ & $4(22.2)$ & $14(77.8)$ & \\
\hline & $>48$ & $16(18.0)$ & $73(82.0)$ & $<0.0001$ \\
\hline
\end{tabular}

${ }^{* *}$ No answer. 


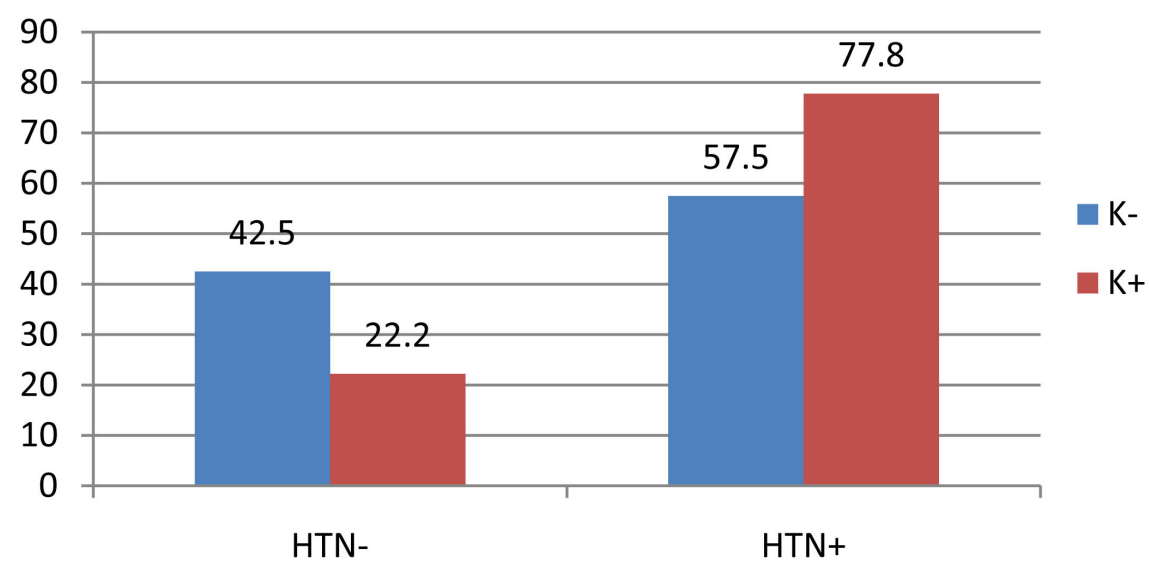

Blood pressure

Diagram 2. Patients knowledge in relation to blood pressure.

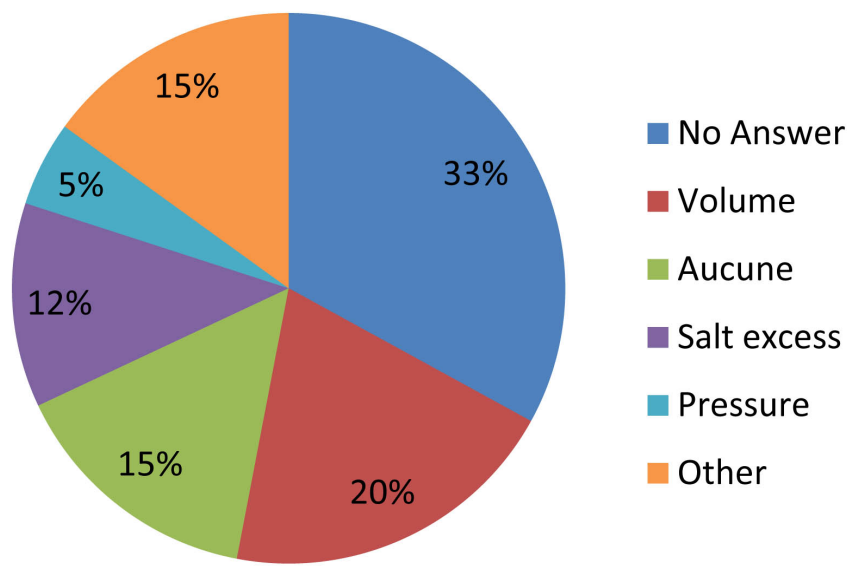

Diagram 3. Summarized concepts on HTN in answer to the question "What is HTN?".

Table 5. Factors associated with HTN knowledge after logistic regression.

\begin{tabular}{ccccc}
\hline Variables & Chi-2 & $p$ & OR & 95\% CI \\
\hline $\begin{array}{c}\text { Level of education } \\
\text { vs Unschooled } \\
\text { Primary }\end{array}$ & $\mathrm{X}^{2}=23.196$ & $<0.0001$ & & \\
Secondary & & 0.215 & $0.058-0.796$ \\
High & & 0.710 & $0.162-3.112$ \\
& & 1.186 & $0.260-5.402$ \\
HTN duration (months) & $\mathrm{X}^{2}=12.090$ & 0.034 & & \\
vs $<6$ & & & \\
$6-12$ & & 0.302 & $0.135-0.675$ \\
$13-24$ & & 0.419 & $0.187-0.940$ \\
$25-36$ & & 0.617 & $0.250-1.520$ \\
$37-48$ & & 0.874 & $0.351-2.176$ \\
$>48$ & & 1.192 & $0.332-4.275$ \\
\hline
\end{tabular}


The duration was also predictive of the knowledge on hypertension. Duration under 6 months as reference the OR for $>48$ months was 1.192 [0.332 - 4.275].

\section{Discussion}

\section{Sample description}

We performed a cross-sectional study of a relatively large sample of outpatients seen consecutively. There were a high proportion of hypertensive patients (69.7\%). This prevalence is much greater than that found by Diallo in 1994 [10] and notes the progression of HTN as emphasized by Fourcade [2] for Sub-Saharan Africa. This increase could be certainly due to a real progression of HTN. Another explanation could be a better screening through increased access (geographically and financially) to health facilities.

The proportion of hypertensive patients increased with the age range as described by several authors [16] [17].

\section{Knowledge about HTN}

Knowledge assessment is a non-standardized field. Developing scales could be a step toward uniformized design study [18] and will allow a better comparison of data from different countries.

In Africa, prevalence data vary from one study to another and from one region to another [4]. Most of them reported data on awareness rather than patients knowledge itself.

Several studies have been carried out and have described a prevalence of patients knowing their HTN status. We found different data from $19.6 \%$ to $84 \%$ [19] and 16.9\%, 29.2\% and 33.7\% respectively for 1990, 2000 and 2010 [5].

Outside Africa, statistics came from China with Wang 42.6\% [20] in the general population or from Canada with McAlister [6] where an improvement from $56.9 \%$ in 1992 to $82.5 \%$ in 2009 was noted.

In our sample among hypertensive patients $67.3 \%$ reportedly had knowledge about HTN. This data seems to be high but hides disparities in the provided definitions. Several concepts have been advanced to define HTN as shown in Diagram 3.

In the African literature, there are few data on factors related to knowledge about hypertension. Niakara in Burkina Faso [21] in his study has pointed out the level of education, as in our model with an odds ratio (OR) of 1.18 compared to unschooled patient. Another factor found in our study was the duration of hypertension, which can easily be explained by the numerous contacts with the practitioner as found by Everett [22]. In our study sex was not found as factor our model (Table 4) contrary to the results of Everett [22]. Factors as found by Li [9] could not be verified in our study due to different study design. From the factors studied by Sanne et al. [23], only HTN duration was found in our study as determinant to knowledge.

\section{Limits}

We performed a cross-sectional study which doesn't allow to assess how much 
information was provided from practitioner. It could be also interesting to look for a better way to provide information, because most patients were unschooled. These questions could be subjects of further studies.

\section{Conclusion}

Our study provided data on HBP knowledge among outpatients with high educational level and HBP duration associated with better knowledge on HBP. These data highlight the need to give patients more information and to extend this study in general population.

\section{Declarations}

\section{- Ethics approval and consent to participate}

Not applicable.

\section{- Consent for publication}

Not applicable.

\section{- Competing interests}

The authors declare that they have no competing interests.

\section{- Funding}

None.

\section{References}

[1] Kearney, P.M., Whelton, M., Reynolds, K., Muntner, P., Whelton, P.K. and He, J. (2005) Global Burden of Hypertension: Analysis of Worldwide Data. Lancet, 365, 217-223. https://doi.org/10.1016/S0140-6736(05)70151-3

[2] Fourcade, L., Paule, P. and Mafart, B. (2007) Arterial Hypertension in Sub-Saharan Africa. Update and Perspectives. MédecineTropicale, 67, 559-567. (Article in French)

[3] Weiland, S.K., Keil, U. and Spelsberg, A. (1991) Knowledge and Attitudes towards Hypertension and Hypercholesterolemia in a Population of Southern Germany: Results from a Population Survey in the Augsburg Area. Soz. Präventivmed, 36, 5-8. https://doi.org/10.1007/BF01322294

[4] Kayima, J., Wanyenze, R.K., Katamba, A., Leontsini, E. and Nuwaha, F. (2013) Hypertension Awareness, Treatment and Control in Africa: A Systematic Review. BMC Cardiovascular Disorders, 13, 54. https://doi.org/10.1186/1471-2261-13-54

[5] Adeloye, D. and Basquill, C. (2014) Estimating the Prevalence and Awareness Rates of Hypertension in Africa: A Systematic Analysis. PLoS ONE, 9, e104300. https://doi.org/10.1371/journal.pone.0104300

[6] McAlister, F.A., Wilkins, K., Joffres, M., et al. (2011) Changes in the Rates of Awareness, Treatment and Control of Hypertension in Canada over the Past Two Decades. Canadian Medical Association Journal, 183, 1007-1013. https://doi.org/10.1503/cmaj.101767

[7] Mendez-Chacon, E., Santamaria-Ulloa, C. and Rosero-Bixby, L. (2008) Factors Associated with Hypertension Prevalence, Unawareness and Treatment among Costa Rican Elderly. BMC Public Health, 8, 275. https://doi.org/10.1186/1471-2458-8-275

[8] Tian, S., Dong, G.H., Wang, D., et al. (2011) Factors Associated with Prevalence, Awareness, Treatment and Control of Hypertension in Urban Adults from 33 
Communities in China: The CHPSNE Study. Hypertension Research, 34, 1087-1092. https://doi.org/10.1038/hr.2011.99

[9] Li, X., Ning, N., Hao, Y., et al. (2013) Health Literacy in Rural Areas of China: Hypertension Knowledge Survey. International Journal of Environmental Research and, 10, 1125-1138. https://doi.org/10.3390/ijerph10031125

[10] Diallo, B.A. (1994) Epidemological Profile of Hypertension in Hospital Area in Bamako. Médecine d' Afrique Noire, 41, No. 2. (Article in French)

[11] BA, H.O., Camara, Y., Sangaré, I., Menta, I., Sidibé, N. and Sanogo, K. (2009) Hypertension and Pregnancy in Bamako: Epidemiological and Clinical Aspects. Mali Médical, 24, 44-47. (In French)

[12] Addo, J., Smeeth, L. and Leon, D.A. (2007) Hypertension in Sub-Saharan Africa: A Systematic Review. Hypertension, 50, 1012-1018.

[13] Bertrand, E., Muna, W.F., Diouf, S.M., Ekra, A., Kane, A., Kingue, S., Kombila, P., Mbaissoroum, M., Niakara, A., Ould, E.A., Sidi Al, A.O. and Yapobi, Y. (2006) Cardiovascular Emergencies in Sub-Saharan Africa. Group Urgences Cardiovasculaires en Afrique Subsaharienne. Archives des Maladies du Coeur et des Vaisseaux, 99, 1159-1165. (In French)

[14] Kearney, P.M., Whelton, M., Reynolds, K., Whelton, P.K. and He, K.J. (2004) Worldwide Prevalence of Hypertension: A Systematic Review. Journal of Hypertension, 22, 11-19. https://doi.org/10.1097/00004872-200401000-00003

[15] Bâ, H.O., et al. (2011) Patient's Knowledge on Hypertension in Hospital Area in Bamako. Journal Africain du Thorax et des Vaisseaux, 1, 44-47. (In French)

[16] Anderson Jr., G.H. (1999) Effect of Age on Hypertension: Analysis of over 4,800 Referred Hypertensive Patients. Saudi Journal of Kidney Diseases and Transplantation, 10, 286-297.

[17] Asmar, R. (2002) Blood Pressure. Regulation and Epidemiology. Measures and Normal Values. EncyclMédChir, Cardiologie, 11-301-A-10, Elsevier, Paris, 15 p. (In French)

[18] Erkoc, S.B., Isikli, B., Metintas, S. and Kalyoncu, C. (2012) Hypertension Knowledge-Level Scale (HK-LS): A Study on Development, Validity and Reliability. International Journal of Environmental Research and Public Health, 9, 1018-1029. https://doi.org/10.3390/ijerph9031018

[19] Bosu, W.K. (2015) The Prevalence, Awareness, and Control of Hypertension Among Workers in West Africa: A Systematic Review. Global Health Action, 8, Article ID: 26227. https://doi.org/10.3402/gha.v8.26227

[20] Wang, J., Zhang, L., Wang, F., Liu, L. and Wang, H. (2014) Prevalence, Awareness, Treatment, and Control of Hypertension in China: Results from a National Survey. American Journal of Hypertension, 27, 1355-1361. https://doi.org/10.1093/ajh/hpu053

[21] Niakara, A., Nebie, L.V.A., Zagre, N.M., Ouedraogo, N.A. and Megnigbeto, A.C. (2003) Hypertension in an Urban Area: Facts and Figures. A Community Based Survey in Burkina Faso. Bulletin De La Societe De Pathologie Exotique, 96, 219-222.

[22] Everett, B. and Zajacova, A. (2015) Gender Differences in Hypertension and Hypertension Awareness among Young Adults. Biodemography and Social Biology, 61, 1-17. https://doi.org/10.1080/19485565.2014.929488

[23] Sanne, S., Muntner, P., Kawasaki, L., Hyre, A. and DeSalvo, K.B. (2008) Hypertension Knowledge among Patients from an Urban Clinic. Ethnicity \& Disease, 18, 42-47. 